\title{
Los otros actores políticos de la campaña electoral
}

ROODY RÉSERVE

\section{Introducción}

"La voluntad general puede dirigir por sí sola las fuerzas del Estado, de acuerdo con la finalidad de su institución, que es el bien común; porque si la oposición de los intereses particulares ha hecho necesario el establecimiento de las sociedades, el acuerdo de estos mismos intereses es lo que lo ha hecho posible. Es lo que hay de común en estos diferentes intereses lo que forma el vínculo social; y si no existiese un punto en el cual se pusiesen de acuerdo todos ellos, no podría existir ninguna sociedad"'. En fin, según Rousseau, el interés público es totalmente diferente de la suma de los intereses particulares; esto es que trasciende los intereses particulares, y si por casualidad alguna vez coinciden, ello se debe a mero accidente.

En las antípodas del planteamiento de Rousseau, Bentham piensa que el estado se gobierna según los intereses particulares. El interés público es la suma de las satisfacciones máximas que pueden ser otorgadas a cada interés particular. El público cree en Rousseau, mientras que cualquier político opera según la concepción de Bentham, tratando de conciliar los intereses opuestos de los grupos, en forma tal que quede cada uno de ellos lo más contento posible". En esta batalla por asegurar la defensa de los intereses propios en las decisiones que toman los responsables políticos, la organización y la capacidad de influencia de los sectores ocupan un lugar destacado. 
La actividad política en cualquier país democrático no puede entenderse fuera de los distintos grupos y fuerzas sociales que intervienen en su curso. No es que la lucha por el poder entre distintas facciones tan solo naciera con el surgimiento de regímenes democráticos, sino que en estos últimos esta lucha cobra un carácter más estable y bastante más previsible. Una costumbre bastante arraigada entre los analistas salvadoreños consiste en analizar la actividad política únicamente desde el prisma de los partidos políticos. Los "otros" actores del sistema político -en este caso, dependiendo de los intereses del analista - suelen ignorarse o, en el peor de los casos calificados como simple marionetas en manos de los partidos. Todo ello se hace en un contexto de demonización de la acción política. Por eso, los actores sociales que desean promover sus proyectos suelen declararse contrarios a los partidos políticos o simplemente apolíticos.

La campaña electoral recién terminada fue un momento privilegiado para observar la actuación de los grupos de presión locales. De manera subrepticia, pero irremediablemente, conforme avanzaba la fecha hacia las elecciones, los diferentes actores sociales van reafirmando su pelaje y simpatías personales en la campaña política. En período pre electoral, es normal que haya incertidumbres y que, de una u otra manera, los distintos grupos hagan oír sus demandas. Desde tiempos inmemoriales, conformarse en grupos de interés ha sido un mecanismo al que han acudido los actores de los colectivos sociales. En palabras de Miguel Jerez, "el grupo de interés es un actor del sistema social que, básicamente, desarrolla la función de articulación de las aspiraciones de individuos o colectivos que, sin ellos, actuarían directamente frente a los poderes públicos en las direcciones más dispares. De este modo, los grupos contribuyen a proporcionar racionalidad, congruencia y viabilidad a las demandas de cuantos comparten una determinada posición frente a otros sectores del sistema social".

En las líneas que siguen se va a intentar una aproximación al estudio de los grupos de presión y su modo de influencia en la vida política. Luego de responder a las preguntas acerca de la identidad y modos de actuación de estos grupos, se hará una breve referencia a la vida política salvadoreña, especialmente durante el contexto de la campaña electoral pasada para aclarar el modus operandi de estos colectivos. 


\section{Del mito del interés general al interés particular}

El estado moderno que hoy conocemos surge en el Renacimiento como territorio, gobierno, cuerpo de leyes, burocracia y, sistema judicial unidos. Frente a las entidades disgregadas de la Edad Media, el estado tiene como vocación superar las divisiones étnicas, regionales que caracterizaban a determinadas realidades geográficas del mundo antiguo. En opinión del filósofo francés Jacques Maritain, “el estado es únicamente esa parte del cuerpo político cuya función específica consiste en mantener la ley, en promover prosperidad común y el orden público y en administrar los negocios públicos. El estado es una parte especializada en los intereses del todo. No es un hombre o un grupo de hombres: es un conjunto de instituciones que se combinan para formar una máquina reguladora que ocupa la cumbre de la sociedad"'.

Esta concepción del estado como el lugar desde donde se defiende el interés supremo de toda la colectividad es parte de una tradición bien conocida en la historia de la filosofía política. Rousseau fue uno de los principales expositores. Frente a las elaboraciones de quienes propugnaban la defensa de los intereses individuales, el pensador suizo pensaba que no había manera de compaginar los deseos de los particulares y el interés general de la sociedad, fuera del Estado. Por eso, descargó en éste un rol de primer orden para mantener la cohesión social. El interés general se encuentra por encima de cualquier demanda o necesidad individual porque en el momento del contrato, "cada uno de nosotros pone en común su persona y todo su poder bajo la suprema dirección de la voluntad general, recibiendo a cada miembro como parte indivisible del todo"3.

La visión anterior del papel del estado no ha hecho unanimidad entre los pensadores políticos del tema. Otros, al contrario, ven en la defensa de los intereses individuales el mejor apoyo desde donde sostenerse el Estado. Los filósofos utilitaristas tuvieron un papel destacado en el cuestionamiento de la vieja concepción filosófica del interés general. "El fin máximo y principal que tienen los hombre al reunirse en estados y someterse a un gobierno - dice Locke- es la salvaguardia de su propiedad, salvaguardia a la que le faltan muchas cosas en el estado de naturaleza" . De modo que no sólo no existe tal interés general, sino que la única vía para acceder al mantenimiento del estado pasa por la defensa de los intereses individuales. 
En este contexto, es perfectamente legítimo que surjan individuos y grupos específicos, reivindicando intereses particulares. Los grupos de interés o grupos de presión ${ }^{5}$ responden a esta idea: la de que es posible y beneficiosa defender los intereses particulares ante las autoridades públicas. Los grupos de presión no se proponen dominar al gobierno entero mediante el control de sus miembros, sino ejercer influencia sobre el mismo para que adopte una política favorable a los objetivos que defienden o aspiran a conseguir. Aunque, un análisis más detallado de estos grupos pueden arrojar resultados más complejos. A veces, algunos grupos de presión no sólo aspiran a controlar totalmente el estado, sino también podría volverse difícil establecer una identidad propia con respecto a ciertos partidos.

\section{Una visión general de los grupos de presión}

No ha existido siempre unanimidad entre los politólogos en torno a la definición y alcance de la expresión "grupos de presión". Antes de conformarse como tal, el grupo de presión suele pasar por un estadio previo considerado como grupo de interés no político. Sucede que, en palabras de Miguel Jerez, "a los grupos de intereses les reulta insuficiente el ámbito del sistema social, necesitando descender a la arena política para difundir y defender sus demandas y reivindicaciones con unas mínimas perspectivas de éxito. Éste es justamente el paso que hace de un grupo de interés un grupo de presión. Por consiguiente, un grupo de interés se convierte en grupo de presión cuando entra en la escena política operando como actor político".

Pero, pese a todas las divergencias, se puede decir que el término grupo de presión hace referencia a los grupos de interés que intervienen en la escena política. Así se denomina grupos de presión a las organizaciones o colectivos de personas (físicas o jurídicas) que pretenden influir a los responsables de tomar decisiones políticas (en los poderes ejecutivo, legislativo y/o judicial), de manera directa o por medio de la opinión pública?. En opinión de Meynaud, los grupos de presión "evocan las luchas emprendidas para que las decisiones de los poderes públicos estén de acuerdo con los intereses de una categoría social dada". Al hablar de grupos de presión, se hace referencia a las acciones que impulsan estos colectivo en vista de obtener ciertos resultados, positivos o negativos, respecto de las decisiones que toman 
las autoridades públicas. Bajo el vocablo grupo de presión -puede decirse- se encuentra una serie variopinta de organizaciones, de objeto y configuración variados. Existen organizaciones que buscan satisfacer intereses propios y exclusivos de sus miembros o afiliados. Algunas organizaciones persiguen la satisfacción de intereses de colectivos indeterminados. En fin, otras organizaciones, no obstante su vocación de defender determinados intereses colectivos, pueden promover también, en determinadas circunstancias, intereses que favorecen a toda la sociedad.

Los grupos de presión son diferentes de los partidos políticos. Mientras que éstos defienden intereses generales, aquéllos abogan por intereses propios y particulares. Sin duda, la principal diferencia entre el grupo de presión y el partido político se encuentra en el hecho de que los grupos de presión no asumen responsabilidades políticas, cosa que sí sucede en el caso de los partidos políticos. Finalmente, "un recurso igualmente válido - para establecer una diferencia entre grupos de presión y partidos políticos- es acudir a las circunstancias de tiempo y espacio, es decir a la conciencia que la gente tenga en cada contexto de lo que es un partido o un grupo de presión"

Por otro lado, los movimientos sociales entendidas como redes de interacciones informales entre individuos, grupos y/o organizaciones que, en una interacción con las autoridades públicas, elites y oponentes piden cambios en el ejercicio o la redistribución del poder a favor de intereses colectivos; estos movimientos sociales se distinguen de los grupos de presión. Mientras los grupos de presión pretenden que el poder político tome decisiones de acuerdo con los intereses que ellos representan, los movimientos sociales no tienen estas pretensiones. Además, los beneficiarios de la acción pública de un movimiento social son bastante indeterminados. En este caso se habla de toda la sociedad

Los grupos de presión tienen funciones variadas. Según Schwartzenberg las funciones de los grupos de presión se pueden agrupar de la siguiente manera: "1) articulación de intereses puesto que presentan demandas a las entidades públicas; 2) información completa a las autoridades sobre el contenido de las medidas que en su concepto deben tomarse, 3 ) aceptación de los interesados respecto de las medidas propuestas, y 4) canalización de las reivindicaciones ante las autoridades públicas ${ }^{n 10}$. 
Jerez distingue cinco grupos principales de presión. “a) organizaciones de empresarios e inversores (influyentes en los sistemas de economía de mercado, son conformadas por grupos industriales y de negocios que buscan intervenir en la vida política); b) sindicatos (suelen agruparse en función de criterios ideológicos"1); c) grupos profesionales y corporativos de clase media (en general, son conformados por ganaderos, granjeros, abogados, médicos etc.); d) grupos de promoción y asociaciones cívicas de iniciativa privada (en algunos casos, se trata de iglesias, grupos confesionales etc.) y ; e) las asociaciones políticas (en algunos países se trata de grupos que representan regiones frente al poder estatal federal"'2.

Los grupos de presión actúan de distinta manera, según el tipo de régimen, los países considerados, la forma de gobierno, o el momento histórico en que presentan sus demandas. Así, entre una gama muy variada en su repertorio de acciones de presión, se pueden enumerar: la persuasión, la amenaza o intimidación, el dinero, el sabotaje de la acción del gobierno u otros medios de acción directa. En cualquier caso, hay que tener presente que "las tácticas de o métodos de actuación de los grupos de presión van, pues, de lo constitucional a lo inconstitucional, y de lo legal a lo ilegal, variando en función de las limitaciones impuestas por las instituciones, las reflementaciones y los valores dominantes en una sociedad dada, y de acuerdo con el objeto sobre el que actúan"13.

$\mathrm{Si}$, como hemos visto, existen grupos de distinta raigambre y que defienden intereses de sectores dispares de la sociedad, no todos cuentan con la misma cuota de influencia ante los responsables políticos. Hay muchas variables que pueden explicar la mayor o menor posibilidad de ser escuchados por parte de las autoridades públicas. El número de sus miembros, la capacidad financiera, la reputación del grupo ante el público, entre otros, son algunos de los elementos que determinan el poder de los grupos de presión"14. Viceversa, se debilitan los grupos de presión la rivalidad con otros grupos para controlar un mismo recurso, menor prestigio ante la opinión pública y la fragmentación entre grupos que persiguen un mismo objetivo ${ }^{15}$.

Una vez presentados las características generales de definición de los grupos de presión, se puede concluir señalando que, en primer lugar no constituyen en sí un peligro para la democracia, más bien según muchos autores contribuyen a fortalecerla. Además, existen al- 
gunos elementos de carácter general que determinan el papel que en cada sistema político desarrollan los grupos de presión. El sistema político de cada país el que determinará la capacidad de influencia de los grupos de presión y, la receptividad de los destinatarios de la misma. Sobre esto último, se considera que en un sistema polírico en el que los parlamentarios son sometidos a una disciplina de partido fuerte es menor la capacidad de influencia de los grupos de presión sobre los diputados. Mientras que en un sistema de partidos de disciplina partidaria débil, como en el caso de los Estados Unidos, la influencia de los grupos de presión es mayor.

\section{El caso de los Estados Unidos ${ }^{16}$}

Estados Unidos fue el primer país en que se llegó a establecer una regulación sobre la actividad de los grupos de presión ${ }^{17}$. En el año 1946 se aprobó la ley reguladora de la actuación de los grupos de presión con la pretensión de delimitar el marco en el que realiza su actividad. Esta ley fue ineficaz debido al hecho de que muchos grupos de presión actuaban al margen de la regulación, aparecían nuevos tipos de actuación y nuevos movimientos que no se avenían con la regulación establecida en 1946. Además, la propia Administración, probablemente por la falta de instrumentos, se había mostrado débil ante la presión ejercida por estos grupos.

Ante esta situación, el Congreso decidió aprobar una nueva ley el 19 de diciembre de 1995, la Lobbying Disclosure Act (Ley de Revelación de Actividades de Presión), con el objetivo de hacer público la identidad y extensión de los esfuerzos de los grupos de presión remunerados (paid lobbyist) para influenciar a los cargos federales (Federal Officials) en las decisiones que tome el gobierno para incrementar la confianza de la ciudadanía en la integridad del gobierno.

La ley instaura un doble sistema de información de las actividades de presión que se realicen: por un lado, se crea un registro en el Senado y en el Congreso en el que se deberán inscribir todos aquellos que realicen actividades de presión; por otro lado, se deberá presentar semestralmente un informe sobre las actividades de presión realizadas. Así, la Ley establece la revelación de los nombres de los grupos de presión o lobbies, sus contratantes, sus clientes, una estimación de 
sus gastos y los temas sobre los que los grupos de presión se comunican con los agentes públicos.

Este doble sistema de información se instaura con el objetivo final de garantizar la transparencia del ejercicio de la actividad de presión por parte de determinados grupos $\mathrm{y}$, también, la transparencia en la actividad de los poderes públicos. Además, para reforzar este principio de transparencia, los documentos y registros previstos por la ley son de acceso público.

\section{¿Quiénes son grupos de presión? ¿Qué hacen?}

Presentados los principales aspectos de la Lobbying Disclosure Act debemos a continuación mostrar algunos elementos definidores del sistema instaurado en los Estados Unidos de América. Antes debemos destacar que llama la atención el complejo aparato conceptual que prevé la ley (por ejemplo, se habla de lobbying contact, lobbying activity, lobbyist, lobbying firm y client), en especial si tenemos en cuenta la finalidad de transparencia que justifica, en última instancia, la aprobación de la ley. Superando las mareas, presentamos las principales definiciones que recoge la ley, para poder posteriormente comentar brevemente los mecanismos previstos.

- Cliente: cualquier persona o entidad que emplea o retiene a otra persona a través de dinero u otro modo de compensación para realizar actividades de presión en nombre de esa persona o entidad.

-Instituciones y cargos protegidos por la ley: La ley protege tanto a cargos del poder ejecutivo (Presidente, Vicepresidente, directivos y empleados de la Oficina del Presidente, directivos y empleados de la Oficina de Programación y otros empleados de determinados órganos) como a miembros del poder legislativo (miembros del Congreso y personal a su servicio, etc).

-Grupos de presión: los grupos de presión pueden tener muy diferente estructura: pueden ser personas individuales, colectivos, empresas dedicadas a ejercer presión. En todo caso, debemos destacar que la Lobbying Disclosure Act no se aplica por igual a todos ellos.

-Actividades de presión (lobbying activities): son los contactos de presión y las gestiones para conseguirlos, incluidas las actividades de preparación y planificación, investigación y otro trabajo previo que 
posteriormente sea utilizado en los contactos de presión, así como también la coordinación con las actividades de presión de otros grupos.

-Contactos de presión (lobbying contacts): son cualquier comunicación oral, escrita o

electrónica con una institución u órgano protegido por la ley que se realiza en nombre de un cliente con el objetivo de conseguir:

a. la formulación, modificación o adopción de una ley federal (incluidos los proyectos).

b. la formulación, modificación o adopción de un reglamento federal, regulación, orden ejecutiva o instrucción (executive order) o cualquier otro programa, política o posición del Gobierno de los Estados Unidos.

c. la administración o ejecución de un programa o política federal (incluidas la negociación, premio o administración de un contrato federal, subvención, préstamo, permiso o licencia).

d. la designación o confirmación-ratificación de una persona para un cargo sujeto a la confirmación del Senado.

No se entenderá como contacto de presión aquella comunicación que:

a. realice un cargo actuando bajo su esfera de competencias.

b. realice un representante de un medio de comunicación si el objetivo de la comunicación es la difusión de información.

c. se realice mediante un discurso, artículo, publicación u otro material que es distribuido al público o a través de un medio de comunicación social.

d. realice un gobierno extranjero o un partido político extranjero bajo la regulación del Foreign Agents Registration Act de 1938.

e. invite a una reunión si no incluye una intención de influenciar en los órganos protegidos por la ley.

f. se realice en el transcurso de la participación en un órgano consultivo sujeto a la Federal Advisory Committee Act.

g. sea fruto del testimonio dado ante un comité, subcomité u otro órgano del Congreso. 
h. sea resultado de la información escrita en respuesta a una pregunta de un órgano protegido por la Ley.

i. sea requerida en un proceso de investigación y, en general, en el seno de procedimiento administrativos.

Tampoco se entenderán como actividades de presión las movilizaciones de calle (grassroots activities) así como otras comunicaciones indirectas (por ejemplo, el envío masivo de cartas o las campañas en los medios de comunicación)

\section{Mecanismos previstos por la LDA}

La Lobbying Disclosure Act prevé tres mecanismos diferentes con el objetivo de garantizar la transparencia de la actividad de los grupos de presión y de los poderes públicos sobre quienes dirigen su actividad:

a. Registro de los grupos de presión

Una persona u organización debe registrarse siguiendo el procedimiento previsto en la LDA cuando cumpla los siguientes requisitos:

- que la persona reciba una compensación

- que la persona realice contactos de presión

- que los contactos realizados no se encuentren bajo ninguna de las excepciones previstas en la definición de contacto de presión.

- que la persona gaste el $20 \%$ o más de su tiempo en actividades de presión.

Es necesario destacar que:

- Una persona que no gaste más del $20 \%$ de su tiempo trabajando para su cliente haciendo presión no se incluiría bajo la definición de la LDA y por tanto no debería registrarse.

- se gastan o reciben unas determinadas cantidades de dinero por las actividades de presión (5.000 o 20.000 dólares, dependiendo de los casos). 
La LDA prevé diferentes mecanismos de inscripción en función de que se sea el cliente, la empresa contratada o su personal.

En todo caso, el registro debe realizarse no más allá de los 45 dias después de que el grupo de presión haya realizado un contacto o haya sido contratado para realizarlo. Realizada la actividad de presión, se debe registrar la finalización de la misma.

\section{b. Informe semestral de las actividades realizadas}

Semestralmente se ha de presentar un informe al Congreso y al Senado donde se mencionen las actividades de presión realizadas durante dicho periodo. En el informe se debe indicar el nombre del grupo de presión, en su caso su cliente, las actividades de presión realizadas, los agentes públicos con quienes se haya contactado, y el total de ingresos recibidos, en su caso, por las actividades de presión realizadas.

\section{c. Otras revelaciones exigidas}

La LDA exige que los grupos de presión y aquellos a quien se presione realicen determinadas revelaciones en el momento en que se realice la actividad. Quien realice un contacto de presión oral o escrito, a petición del agente del gobierno sobre el que se haga el contacto, debe:

- revelar si se ha registrado siguiendo la LDA;

- identificar a su cliente;

- informar sobre si la entidad de presión es extranjera.

Por su parte, aquellos sobre los que se realice la presión deben manifestar si se encuentran bajo la protección de la LDA.

\section{Las garantías de la LDA}

El Secretario del Senado y el Clerk del Congreso son los encargados de velar por el cumplimiento de la Ley. Además están facultados para dictar instrucciones para facilitar su cumplimiento. No obstante, no tienen potestad para investigar, por lo que cuando detecten un incumplimiento de la ley lo deberán comunicar al fiscal del Distrito de Columbia (U.S. Attorney for the District of Columbia). 
En todo caso, la propia ley prevé un sistema sancionador con multas (civil penalties) de hasta 50.000 dólares.

\section{Modificaciones de la LDA}

El 6 de abril de 1998 se aprobó una modificación de la Lobbying Disclosure Act, la Lobbying Disclosure Technical Amendments Act, que la modifica en tres puntos principales:

- clarifica quiénes se encuentran recogidos bajo la expresión agentes protegidos.

- clarifica las comunicaciones que se entienden bajo la definición de contacto de presión y sus excepciones.

- exenciones de la Foreign Agents Registration Act para aquellos grupos que se hayan registrado siguiendo a la Lobbying Disclosure Act.

\section{Los grupos de presión en El Salvador}

En el caso salvadoreño, el tema de la existencia y funcionamiento de los grupos de presión aún no es parte del debate público. Lo anterior no significa que no existan estas organizaciones (hablaremos más adelante de ello) sino que no se han estudiado y ni ellas mismas se denominan de esta manera. No obstante, existe una ley que regula las asociaciones y fundaciones sin fines de lucro que podría considerarse como lo más cercano a una legislación en esta materia. El quinto considerando de la misma establece que "es necesario la creación de un registro de asociaciones y fundaciones sin fines de lucro, a fin de contar con un instrumento de publicidad formal de su creación, organización y dirección, que brinde seguridad jurídica a dichas personas, a sus miembros y a terceros que contraten con ellos"18.

Una lectura de esta ley, sin embargo, permite observar que en ningún momento trata de los grupos de presión tal como se conocen a la luz del caso estadounidense citado. No sólo no sigue este camino, sino que define las organizaciones sin fines de lucro en términos tan asépticos que no parecen tener ninguna relación con la vida política del país. En determinadas cuentas, se habla de las organizaciones y/o fundaciones sin fines de lucro porque su "esfuerzo y trabajo ha brindado resultados positivos en el mejoramiento de las condiciones de 
vida de muchas familias salvadoreñas y que además permite destacar la importancia social que estas personas jurídicas realizan en el desarrollo económico y social del país".

Así como las leyes no hacen referencia alguna a las organizaciones sin fines de lucro en términos de grupos de presión, estas últimas tampoco suelen presentarse como organismos que intervienen en la vida política. Por ejemplo, en el documento de fundación de la Asociación Nacional de la Empresa Privada (ANEP) se declara que, entre otros, tiene como objetivo: "coordinar los esfuerzos de la iniciativa privada, en beneficio del desarrollo económico, social y cultural del país. Prestar su colaboración en la solución de problemas nacionales de índole económica, financiera, social o legal; Colaborar en lo relativo a la promoción y canalización adecuada de las inversiones nacionales y extranjeras, que tienden a fortalecer la economía nacional; Asesorar y presentar recomendaciones a las Entidades Asociadas, en lo relativo a los problemas que las afectan; Fortalecer la unidad de las Entidades Asociadas en cuestiones de interés general; conciliar las diferencias que puedan existir entre éstas, y servir de arbitro en los asuntos de aquellas para los cuales sea requerida; Abogar por la Vigencia de un régimen económico que responda a principios de justicia social y al respeto de la persona y que establezca condiciones apropiadas al desarrollo y estimulo de la empresa privada. Procurar la armonía de las relaciones entre los sectores empresarial y laboral, sobre las bases de equidad y justicia, con miras al interés general; y Realizar todas aquellas actividades que tiendan a desarrollar, beneficiar y fortalecer la iniciativa privada"19.

Como puede observarse, en seguida, de estos objetivos citados por la ANEP, en ningún momento se habla abiertamente de defender exclusivamente los intereses de los empresarios. $\mathrm{Ni}$ siquiera en las acciones de presión efectivas de estos grupos se reconoce que se trabaja en beneficio de un grupo de personas. En el último encuentro de los empresarios ENADE 2003, Gobernabilidad en democracia, se trataba de llamar la atención de los dirigentes del país sobre la necesidad de "aprovechar las ventajas y enfrentar los desafíos que ofrece el mercado global. (...) Desde la perspectiva empresarial -se decía-, El Salvador necesita con urgencia reforzar su andamiaje institucional, para consolidar la democracia, asegurar el crecimiento sostenido con equidad y garantizar la paz social"20. 
Esta forma de presentar su propia labor hace recordar el viejo truco de la asepsia política que suelen usar los grupos de presión. "Muy frecuentemente encontramos en nuestros grupos la pretensión de una posición apolítica. Sin embargo, esta aserción no deja de asombrarnos, ya que, como afirma Meynaud, las intervenciones sobre el aparato gubernamental son innumerables, y los contactos entre los responsables públicos y privados prosiguen rigurosamente y se mantienen a veces en forma cotidiana. ecómo conciliar esta situación con la pretensión de hacer política que pregonan los dirigentes de las organizaciones profesionales e incluso, en circunstancias diversas, los dirigentes de agrupaciones de vocación ideológica? se trata de una declaración sincera, de la consecuencia de una miopía o de una voluntad premeditada de mistificación?"21.

En cada caso, habrá que buscar una respuesta satisfactoria a las preguntas de Meynaud. Sin embargo, no cabe duda que las distintas organizaciones salvadoreñas hacen política y hacen presión sobre los gobernantes para que adopten sus puntos de vista sobre los problemas en que intervienen. Los encuentros anuales que celebra la empresa privada para dar a conocer su opinión sobre la ruta correcta que debería de tomar el país; los centros de estudio, afines a determinados grupos económicos que presentan "estudios científicos" para marcar el paso de la vida socio política y económica nacional o los sindicatos que organizan encuentros multitudinarios para presentar sus demandas; todas estas actividades políticas y consisten en mecanismo distintos para presionar a los gobernantes.

La última campaña electoral ha sido un momento privilegiado para observar el compromiso político de los distintos grupos de presión. Todavía en el país no está regulado el tema del financiamiento de los partidos políticos, éstos tampoco tienen la obligación de divulgar el origen de sus fondos. De esta manera, es casi imposible diseñar una investigación que establezca una relación objetiva entre las declaraciones públicas de los dirigentes de los grupos de presión y su contribución pecuniaria a la campaña de los candidatos que defienden. En todo caso, como sostienen muchas publicaciones locales, durante la campaña para las últimas elecciones, distintos grupos desvelaron su pelaje. No sólo que algunos responsables manifestaron su simpatía con la izquierda ${ }^{22}$, sino que también las agrupaciones empresariales manifestaron sin escrúpulos sus simpatías políticas. "No es desatina- 
do sostener que la campaña de ARENA no sólo fue una campaña mediática, sino que las elecciones fueron ganadas por los grandes medios de comunicación. ARENA no ganó por sus propuestas y planes de gobierno; de hecho, la mayoría de sus votantes - gente pobre de las zonas urbanas y rurales- no tiene ni la más remota idea de lo que el partido de derecha le ofrece en términos de políticas económicas y sociales. ARENA ganó, en parte, porque las grandes empresas mediáticas hicieron del miedo el principal argumento de convencimiento (o de chantaje) social. Y no se detuvieron ante nada, violando incluso la misma legislación electoral que prohibía hacer campaña durante el día de los comicios" 23 .

También los grupos de presión salvadoreños han entendido que es necesario dominar la comunicación y gozar de buen prestigio ante la opinión pública. No es raro encontrar en la prensa nacional elogios desbordantes a determinadas organizaciones empresariales. En las reuniones de la ANEP y FUSADES, pro citar solamente estos dos, suelen representarse las más altas autoridades estatales. Mientras que en el caso de los sindicatos, se suele presentar sus demandas como quimeras descabelladas o de violentos que ponen en peligro la estabilidad nacional. Frente a los elogios y la presencia de las autoridades públicas en las reuniones de la ANEP, por ejemplo, en ningún momento han hecho acto de presencia las autoridades locales en las reuniones de los sindicatos. Al contrario, cuando alguna organización política de izquierda manifiesta su simpatía por estos últimos, los medios suelen hablar de politización a ultranza y connivencia peligrosa de sindicatos y políticos.

Finalmente, como se ha dicho al inicio de estos comentarios los grupos de presión son inherentes a la estructuración de las sociedad modernas y que desempeñan un papel relevante en las sociedades democráticas en que están implantados. Sin embargo, no es ocioso apuntar que en alguna ocasión pueden presentar un cierto peligro para la vida democrática. Cuando un solo grupo detenta una cuota de poder que no deja lugar para la participación de los demás o que hay una connivencia perniciosa entre determinados grupos y ciertos decisores políticos. En estos casos, la democracia puede correr mucho peligro. 
1. Rousseau, J. J., El contrato social, Editorial Tecnos, Madrid, 1987, p. 25.

2. Jacques Maritain, El Hombre y el Estado, Buenos Aires, Edit Kraft, 1952 pp.1719.

3. Rousseau, op. cit. p.15

4. Locke, J. Ensayo sobre el gobierno civil, Madrid, Aguilar, 1969.

5. Más adelante se introducirá la discusión acerca de la diferencia entre uno y otro. Por el momento se va a manera el término como sinónimo.

6. Jerez, M., Manual de ciencia política, Trotta, 1997, p.297

7. Ibid.

8. Citado por Sanglemente Molina en: Grupos de presión, Bogotá, Tercer Mundo, 1965 p.18.

9. Jerez, op.cit. p. 302

10. Citado por Galvis Gaitán, F. en: Manual de ciencia politica, Editorial Tenis, Santafe de Bogotá, 1998, p. 187.

11. Jerez identifica tres tipos ideales que suelen acompañar está agrupación ideológica que son: 1) el modelo pluralista de asociaciones fragmentadas con varias organizaciones prestigiosas dentro de las organizaciones de la cúpula. 2) el modelo corporativo, integrado por sindicatos unitarios, de orientación socia demócrata, con asociaciones organizadas según el modelo industrial. 3) el modelo latinoamericano, compuesto de centrales separadas desde un punto de vista organizativo y unidas por una misma ideología que suele ser comunista. Jerez, ibi. p. 303.

12. Ver Jerez ibid. pp. 291-307.

13. Ibid. Pp.308-311.

14. Arias, grupos de presión en Costa Rica, Editorial Costa Rica, San José, 1971.

15. Ibid. p.78.

16. En esta sección se presenta un resumen del texto de Agustí Cerrillo, La regulación de los grupos de presión: El sistema de los Estados Unidos de América y de la Unión Europea, Publicado por el institut de gobemabilitat de catalunya en colección de Papers: http://www.iigov.org/papers/?p=1_0012.

17. Hay que notar que no se llegó a esta decisión por generación espontánea. Al contrario, hubo muchas voces contrarias a la actividad de los grupos de presión, los cuales algunos consideraban perniciosas para las aspiraciones de un régimen, cuya vocación está en la defensa de los intereses de la mayoría de los ciudadanos. A este respecto se preguntaba Woodrow Wilson: "la pregunta principal cuando se examina cualquier sistema de gobierno debe referirse, naturalmente, a los verdaderos depositarios y a la maquinaria esencial del poder. Existe siempre un centro de poder; en este sistema, ¿dónde está ese centro? ¿En qué manos reside la autoridad suficiente, $y$ a través de qué mecanismo habla y actúa? A estas preguntas respondería Harrington describiendo la situación de los pobres en los Estados Unidos. Observa que la "miseria se va quedando aislada y oculta. Los pobres han terminado por ser políticamente invisibles (...), ellos no tienen lobbies, no tienen cara $y$ han terminado por no tener voz". Citado por Carter Douglas, el poder y los grupos de presión, Ramdom House-Nueva York, U.S.A., 1965. Pp. 28-53.

18. Ver Ley de Asociaciones y Fundaciones sin Fines de Lucro. 
19. Ver Estatutos de la ANEP en : http://www.anep.org.sv/informacion_general.htm

20. Ver documento del Encuentro Nacional de la Empresa Privada, "Gobernabilidad en democracia", 2003.

21. Arias, op.cit. p.80.

22. El caso de los médicos en huelga, cuyo dirigente terminó siendo el candidato a la vicepresidencia del partido de izquierda ilustra bien este hecho.

23. Además, esta actitud comprometida de buena parte de la prensa tiene que verse en consonancia con la postura de muchos otros grupos de presión simpatizantes del partido ARENA. Ver "El cuarto triunfo de ARENA", editorial, en Proceso, Año 24, $N^{\circ}$ 1091, San Salvador 24 de marzo de 2004. 